\title{
Assessment of immunological techniques in the diagnosis and prognosis of ocular malignant melanoma
}

\author{
ALISTAIR J COCHRAN, ${ }^{1}$ WALLACE S FOULDS, ${ }^{2}$ BERTIL E DAMATO, ${ }^{2}$ \\ GRAHAM E TROPE, ${ }^{2}$ LINDSAY MORRISON,${ }^{3}$ AND WILLIAM R LEE ${ }^{3}$ \\ From the 'Division of Surgical Oncology, John Waine Clinic and Armand Hammer Laboratory, and \\ Department of Pathology, Center for Health Sciences, University of California, Los Angeles, 90024, USA; and \\ the Departments of ${ }^{2}$ Ophthalmology and ${ }^{3}$ Pathology, Western Infirmary, Glasgow
}

SUMMARY Tests of cell mediated immunity (one and two stage leucocyte migration inhibition assays) and humoural immunity (membrane immunofluorescence and serum effects on leucocyte migration) were done with leucocytes and sera from 36 patients with uveal melanoma, five with conjunctival melanoma, 21 with non-malignant ocular disease, and 189 with cutaneous melanoma. Cell mediated reactivity with melanoma extracts and serum reactivity with cultured melanoma cells were significantly more frequent in the melanoma patients, but control donor reactivity was also relatively high. Maximum reactivity was found with cells or serum from those patients in whom, on pathological examination, the intraocular melanoma had penetrated the sclera and in patients with conjunctival melanoma. Maximum separation of melanoma patients from control donors was achieved by consideration of the results of several tests done simultaneously. These immunopathological studies were made during the period from 1972 to 1978. At follow-up in 1983 four of the five patients suffering from conjunctival melanoma had died from metastases, and 10 of the 36 with uveal melanoma had died from metastatic disease. The immunological reactions, while of some value in separating melanoma patients from those without melanoma, did not predict whether a particular patient with uveal melanoma would die of metastatic disease or would survive.

In eyes with clear media malignant melanoma of the uveal tract seldom presents a significant diagnostic problem. This is because of the application of supplementary techniques such as ${ }^{32} \mathrm{P}$ uptake, fluorescein angiography, and ultrasonography. ${ }^{12}$ However, with opaque media, and occasionally even with clear media, assessment of a possible tumour may remain difficult. Current and fundamental problems include a basic lack of understanding of the factors that govern the biological behaviour of ocular melanoma. In particular there is no possibility of our being able to assess the chances of long-term survival for the individual patient, though statistical analysis of large numbers of enucleated eyes has emphasised the importance in prognosis of factors such as tumour size, cell type, and the presence or absence of extraocular spread at enucleation. ${ }^{3}$ A factor to be taken into account when the nature and mechanisms of metastatic disease are under consideration is the host-tumour relationship. This is also relevant to the

Correspondence to Alistair J Cochran, MD. therapeutic techniques currently under investigation (local excision, irradiation modes of various types, light and laser coagulation etc.). ${ }^{2}$

The immune status of patients with uveal melanoma has been the subject of intensive research for some 15 years, ${ }^{4}$ and studies of humoural immunity or cell mediated immunity have shown that in a significant proportion of patients with uveal melanoma there is in-vitro evidence of tumour related immune reactivity.

However, similar in-vitro tests also show immune reactivity to melanoma antigens in a smaller percentage of control patients. In an attempt to refine immunopathological investigations we correlated simultaneous tests of humoural and cell mediated immunity in 36 patients with uveal melanoma and five patients with conjunctival melanoma during the period 1972-8. The results are presented in relation to the pathological findings and survival data for patients over not less than five years. The results from ocular melanoma patients are compared with data compiled for patients with cutaneous melanoma. 


\section{Patients and materials}

Leucocytes and serum were available from 41 patients $(27 \mathrm{f}, 14 \mathrm{~m})$ with malignant melanoma of the eye and 21 patients with non-malignant ocular conditions. The melanoma was in the choroid of $\mathbf{3 0}$ patients, in the ciliary body or iris in six patients, and on the conjunctiva in five patients. The clinical details and pathological diagnoses were not known to the people undertaking the immunological studies at the time they did them.

Blood samples were also obtained from 120 patients with cutaneous melanoma and 153 with nonmelanomatous malignancy or non-malignant conditions. This material has been described in detail elsewhere. ${ }^{5}$

Assessment of cell mediated immunity. This was examined (1) by a one-stage capillary leucocyte migration assay modified from the technique of Bendixen and Søborg ${ }^{6}$ and described by Ross et al., ${ }^{7}$ and (2) by a two-stage lymphokine generation assay using normal human peripheral blood leucocytes as indicator cells. ${ }^{8}$

Blocking activity in the patients' sera and inherent serum inhibitory activity were examined by a modification of the capillary leucocyte migration assay." Humoural immunity was tested by an indirect membrane immunofluorescent technique employing monolayers of malignant melanoma cells grown on flying coverslips in Leighton tubes.

\section{oCUlaR PATHOLOGY}

Excised globes or tumour tissues were fixed in $2 \%$ glutaraldehyde and processed through paraffin. Sections from several blocks from each tumour were cut at 6-8 $\mu \mathrm{m}$ and stained with haematoxylin and eosin, reticulin (Gordon and Sweet), and Masson Fontana for melanin.

During the macroscopic examination of excised globes the eyes were examined for extraocular exten- sion, and the vortex veins were removed for separate histological examination. Evidence of trans-scleral or episcleral tumour extension was looked for, and appropriate blocks were taken for histological confirmation. Approximate tumour volume was calculated by measuring the tumour diameter (d) in three planes and applying the formula:

$$
V=\frac{4}{3} \pi\left(\frac{d^{1}}{2} \times \frac{d^{2}}{2} \times \frac{d^{3}}{2}\right)
$$

Statistical analysis. Reaction frequencies in the different subgroups were compared by the $\chi^{2}$ test with Yates's correction for small numbers where appropriate. The difference between two groups was accepted as significant when $\mathrm{p}$ was less than $0 \cdot 05$.

\section{Results}

The data were analysed for melanomas arising at different sites within the eyeball and on the conjunctiva (Table 1). A majority of patients reacted (a) in the leucocyte migration assay when medium supplemented with fetal calf serum was used to suspend the melanoma antigen and $(b)$ in the membrane immunofluorescence test. A smaller but still substantial proportion of patients' leucocytes were inhibited by melanoma antigens suspended in medium supplemented with autologous serum in the leucocyte migration assay. A smaller proportion showed leucocyte migration inhibition in medium supplemented with autologous serum without added melanoma antigen. While reactivity seemed higher in the conjunctival melanoma patients, the number of such patients studied was small.

Reactions of ocular melanoma patients compared with controls. The migration of leucocytes from melanoma patients was frequently inhibited by exposure to formalinised melanoma cells (FMC) in the one-stage capillary migration assay with fetal calf

Table 1 Immunological reactions of patients with ocular melanomas subdivided by site of primary tumour

\begin{tabular}{|c|c|c|c|c|c|c|}
\hline \multirow[t]{4}{*}{ Technique } & \multicolumn{6}{|c|}{ Site of melanoma } \\
\hline & \multirow{2}{*}{\multicolumn{2}{|c|}{$\frac{\text { Choroid }}{\text { Positive* }^{*}}$}} & \multirow{2}{*}{\multicolumn{2}{|c|}{$\begin{array}{l}\text { Ciliary body/iris } \\
\text { Positive }\end{array}$}} & \multirow{2}{*}{\multicolumn{2}{|c|}{$\begin{array}{l}\text { Conjunctiva } \\
\text { Positive }\end{array}$}} \\
\hline & & & & & & \\
\hline & Total & $\%$ & Total & $\%$ & Total & $\%$ \\
\hline Leucocyte migration FMC in medium with $10 \%$ FCS & $22 / 30$ & 73 & $3 / 4$ & 75 & $5 / 5$ & 100 \\
\hline Leucocyte migration FMC in medium with $10 \%$ autologous serum & $13 / 20$ & 65 & $2 / 4$ & 50 & $4 / 4$ & 100 \\
\hline Leucocyte migration in medium with $10 \%$ autologous serum without FMC & $5 / 20$ & 25 & $1 / 4$ & 25 & $2 / 4$ & 50 \\
\hline Membrane immunofluorescence & $16 / 22$ & 73 & $3 / 4$ & 75 & $3 / 4$ & 75 \\
\hline
\end{tabular}

*Number of positive tests/total of individuals tested.

FMC = formalinised melanoma cells. 
Table 2 Immunological reaction of patients with ocular or cutaneous melanoma and control donors

\begin{tabular}{|c|c|c|c|c|c|c|c|c|c|c|c|c|}
\hline \multirow[t]{4}{*}{ Technique } & \multicolumn{8}{|c|}{ Melanoma patients } & \multicolumn{4}{|c|}{ Control donors } \\
\hline & \multirow{2}{*}{\multicolumn{2}{|c|}{$\frac{\text { All ocular }}{\text { Positive }}$}} & \multirow{2}{*}{\multicolumn{2}{|c|}{$\begin{array}{l}\text { Intraocular } \\
\text { Positive }\end{array}$}} & \multirow{2}{*}{\multicolumn{2}{|c|}{$\begin{array}{l}\text { Conjunctival } \\
\text { Positive }\end{array}$}} & \multirow{2}{*}{\multicolumn{2}{|c|}{$\begin{array}{l}\text { Cutaneous } \\
\text { Positive }\end{array}$}} & \multirow{2}{*}{\multicolumn{2}{|c|}{$\frac{\text { Ocular }}{\text { Positive }}$}} & \multicolumn{2}{|c|}{ Non-ocular } \\
\hline & & & & & & & & & & & Positive & \\
\hline & Total & $\%$ & Total & $\%$ & Total & $\%$ & Total & $\%$ & Total & $\%$ & Total & $\%$ \\
\hline $\begin{array}{l}\text { Leucocyte migration FMC in medium supplemented } \\
\text { with fetal calf serum }\end{array}$ & $31 / 40$ & 78 & $26 / 35$ & 74 & $5 / 5$ & 100 & $99 / 120$ & 83 & $4 / 11$ & 36 & $67 / 189$ & 35 \\
\hline $\begin{array}{l}\text { Leucocyte migration FMC in medium supplemented } \\
\text { with autologous serum }\end{array}$ & $19 / 32$ & 59 & $15 / 28$ & 54 & $4 / 4$ & 100 & $39 / 71$ & 55 & $3 / 9$ & 33 & $4 / 43$ & 9 \\
\hline $\begin{array}{l}\text { Leucocyte migration in medium with autologous serum } \\
\text { without FMC }\end{array}$ & $13 / 41$ & 32 & $11 / 37$ & 30 & $2 / 4$ & 50 & $42 / 89$ & 48 & $4 / 21$ & 19 & $14 / 100$ & 14 \\
\hline Membrane immunofluorescence & $25 / 34$ & 74 & $22 / 30$ & 73 & $3 / 4$ & 75 . & $48 / 83$ & 58 & $4 / 11$ & 36 & $13 / 57$ & 23 \\
\hline Two-stage assay & $3 / 9$ & 33 & $3 / 9$ & 33 & NT & NT & $31 / 65$ & 48 & NT & NT & $5 / 38$ & 13 \\
\hline
\end{tabular}

NT $=$ not tested

serum as the additive (Table 2). The frequency of inhibition (31 out of $40,78 \%$ ) is similar to that observed in patients with cutaneous melanoma $(83 \%)$. In comparable experiments the leucocytes of ocular disease control donors (4 out of $11,36 \%$ ) and of other control donors (67 out of $189,35 \%$ ) were significantly less frequently inhibited $(p<0.005$ in both cases). When autologous serum (AS) was substituted for fetal calf serum in the migration medium, melanoma patients' leucocytes were inhibited significantly more frequently (ocular 19 out of $32,59 \%$ ); cutaneous 39 out of $71,55 \%$ ) than leucocytes from non-ocular control donors ( 4 out of $43,9 \%-p<0.05$ ). In a small group of ocular control donors leucocyte inhibition in medium supplemented with AS was not significantly less frequent ( 3 out of $9,33 \%$ ) than that observed with the melanoma patients (19 out of 32 , $59 \%)$.

When leucocytes were exposed to AS without the addition of FMC, uveal melanoma patients' leucocytes were inhibited moderately frequently ( 13 out of $41,32 \%$ ), a rate that did not differ significantly from that of cutaneous melanoma patients (42 out of 89 , $48 \%$ ) or ocular controls ( 4 out of $21,19 \%$ ), though non-ocular controls (14 out of $100,14 \%-p<0.025)$ reacted significantly less frequently.

Uveal melanoma patients were tested in a twostage assay, and although the frequency of reaction ( 3 out of $9,33 \%$ ) was higher than that observed with non-ocular control donors ( 5 out of $38,13 \%-N S$ ), it was significantly lower than that observed with cutaneous melanoma ( 31 out of $65,48 \%$ ) and with ocular melanoma patients in the one-stage assay $(\mathrm{p}<0.05)$.

In a study of humoural immunity employing membrane immunofluorescence of monolayer tissue cultures of cutaneous melanoma cells 25 out of 34 ocular melanoma patients tested $(74 \%)$ gave a positive reaction, a frequency similar to that of cutaneous melanoma patients ( 48 out of $83,58 \%$ ) but significantly higher than that of ocular controls (4 out of $11,36 \%-p<0.05)$ or non-ocular controls ${ }^{5}$ (13 out of $57,23 \%-p<0.001)$.

Patient reactivity related to clinical stage. This was considered from two standpoints. First, we considered patients who showed distant spread of their tumour. At the time of testing, only three patients had spread of disease beyond the primary ocular site, in each case by haematogenous spread to remote viscera. Only one of these patients showed a positive reaction to FMC in the leucocyte migration assay (in the presence of FCS). The other assays were done on only one patient and were all negative.

The second aspect of stage of tumour progression considered was microscopic evidence of local extraocular extension (that is, trans-scleral, episcleral, or orbital tumour). (Table 3). Regardless of the immunological technique employed the reaction frequency of patients with evidence of extraocular extension was higher than that of patients in whom the tumour was confined to the globe. The differences were statistically significant with the exception of those observed with the leucocyte migration assay in the presence of autologous serum.

Follow-up of the patients in this study to 1983, five years or more, has shown that four of five with conjunctival melanoma and 10 of 36 with intraocular melanoma died from metastatic melanoma. The pattern of immunological tests did not have significant characteristics in the individual patients who subsequently died from metastases.

Correlation of immunological reactivity of patients 
Table 3 Reaction of uveal melanoma patients with melanoma cells, related to presence or absence of histological evidence of local extraocular spread. Data only from patients whose eye specimens were available for histological study in Glasgow are presented

\begin{tabular}{|c|c|c|c|c|c|}
\hline \multirow{4}{*}{ Technique } & \multicolumn{5}{|c|}{ Intra- or episcleral spread } \\
\hline & \multirow{2}{*}{\multicolumn{2}{|c|}{$\frac{\text { Yes }}{\text { Patients }}$}} & \multirow{2}{*}{\multicolumn{2}{|c|}{$\frac{\text { No }}{\text { Patients }}$}} & \multirow{3}{*}{$p$} \\
\hline & & & & & \\
\hline & Total & $\%$ & Total & $\%$ & \\
\hline $\begin{array}{l}\text { Leucocyte migration FMC in } \\
\text { medium with } 10 \% \text { FCS }\end{array}$ & $8 / 8$ & 100 & $10 / 16$ & 63 & $<0.05$ \\
\hline $\begin{array}{l}\text { Leucocyte migration FMC } \\
\text { in medium with } 10 \% \\
\text { autologous serum }\end{array}$ & $4 / 6$ & 67 & $7 / 15$ & 47 & $>0.50$ \\
\hline $\begin{array}{l}\text { Leucocyte migration in medium } \\
\text { with } 10 \% \text { autologous serum } \\
\text { without FMC }\end{array}$ & $5 / 8$ & 63 & $4 / 20$ & 20 & $<0.05$ \\
\hline $\begin{array}{l}\text { Membrane } \\
\text { immunofluorescence }\end{array}$ & $7 / 7$ & 100 & $10 / 19$ & 53 & $<0.05$ \\
\hline
\end{tabular}

with ocular malignant melanoma and the histological features of their tumours. We related the presence or absence of reactivity in the immunological tests to conventional histological and cytological features of the patients' tumours: spindle or epithelioid cell cytology, the degree of melanogenesis, mitotic rate, and presence and extent of lymphocytic infiltration. We found no significant correlation between the various histological criteria and immunological reactivity and non-reactivity.

Discrimination between patients with uveal melanoma and those with other ocular diseases on the

Table 4 Discrimination between patients with ocular melanoma and those with other ocular diseases on the basis of number of tests done

\begin{tabular}{|c|c|c|c|c|}
\hline \multirow[t]{3}{*}{ Number of tests } & \multirow{2}{*}{\multicolumn{2}{|c|}{$\begin{array}{l}\begin{array}{l}\text { Patients with } \\
\text { intraocular } \\
\text { melanoma }\end{array} \\
\text { Positive }\end{array}$}} & \multirow{2}{*}{\multicolumn{2}{|c|}{$\begin{array}{l}\begin{array}{l}\text { Ocular } \\
\text { controls }\end{array} \\
\text { Positive }\end{array}$}} \\
\hline & & & & \\
\hline & Total & $\%$ & Total & $\%$ \\
\hline One test positive (A) & $26 / 35$ & 74 & $4 / 11$ & 36 \\
\hline One test positive (B) & $22 / 30$ & 73 & $4 / 11$ & 36 \\
\hline One test positive (C) & $11 / 37$ & 30 & $4 / 21$ & 19 \\
\hline Two tests positive $(A+B)$ & $16 / 30$ & 53 & $1 / 9$ & 11 \\
\hline Three tests positive $(A+B+C)$ & $9 / 29$ & 31 & $1 / 9$ & 11 \\
\hline
\end{tabular}

$A=$ Leucocyte migration inhibitions by melanoma cells in fetal calf serum or autologous serum. $B=$ Membrane immunofluorescence vs cultured melanoma dells. $\mathrm{C}=$ Leucocyte migration inhibition by autologous serum in the absence of added tumour antigen. basis of the number of positive tests. A comparison of uveal melanoma patients and control donors showed that a higher proportion of the tumour patients reacted positively in the leucocyte migration assay in the presence of tumour antigen, in the membrane immunofluorescence test, and in the assay studying the effect of autologous serum on leucocyte migration in the absence of added antigen (Table 4). A relatively high proportion of the ocular control donors also reacted, especially in the first two tests. We therefore combined the patterns of reaction in the different tests in various ways to see whether this would better separate the two populations and provide a more specific indication of the presence of ocular melanoma. This was achieved when we compared those who reacted in two or three tests. However, with three tests the absolute proportion of ocular melanoma patients who reacted dropped to an unacceptably low $31 \%$. When we combined reactivity in the leucocyte migration assay in the presence of antigen and in the immunofluorescence technique, we found that $56 \%$ of ocular melanoma patients reacted in both tests, whereas only one of nine $(11 \%)$ of the ocular controls reacted in both. This was the optimum combination of tests that minimised 'false positive' reactions in controls.

\section{Discussion}

There is now considerable evidence that in-vitro tests show tumour-directed antibodies in the serum of patients with uveal or conjunctival melanoma. The percentage of patients with such antibodies in our series ( 25 out of $34,73 \%$ ) compares favourably with the $78 \%$ (57 out of 73 ) reported by Felberg et al. ${ }^{10}$ The complexity of the immunocytochemical problems in the assessment of tumour antigenicity was described by Rahi" in 1971, and it is not surprising that there has been variation in results from different centres. The detection of humoural antibodies to melanoma cells has been confounded by cross-reactivity, for example the presence of antiactin antibodies ${ }^{12}$ in melanoma patients and controls. Ostensibly antimelanoma antibodies were found in our series in four of $11(36 \%)$ ocular controls, but only in four in 33 $(12 \%)$ of the combined skin and uveal controls. This is similar to the false positive rate reported by Felberg et al. ${ }^{10}$ ( 25 out of $\left.106,24 \%\right)$. However, modification of the immunofluorescence technique by absorption has significantly improved specificity. ${ }^{13}$

In-vitro tests of cell mediated immunity in uveal melanoma show variable results when antigens are obtained from different ocular melanomas. ${ }^{14}$ is This is probably the main reason for the lack of consistency shown by different studies carried out to date. 
We have examined the usefulness of combinations of various in-vitro immunological tests to discriminate between patients with malignant melanomas, patients with non-malignant ocular conditions, and normal people without clinically apparent ocular disease.

In assessing individual tests we found that all were more often positive in patients with ocular melanoma than in the control groups. The high frequency of reaction of the ocular melanoma patients in both the one-stage leucocyte migration assay against melanoma-associated antigens and the membrane immunofluorescence technique is encouraging. However, there was also a comparatively high frequency of reaction in control donors, particularly the ocular control donors, in these tests. Discrimination is considerably improved when we assess the concurrence of positive results in the leucocyte migration assay and the membrane immunofluorescence test done simultaneously. This gave excellent separation of ocular melanoma patients and the control donors, but unfortunately the absolute frequency of reaction in the melanoma group dropped to $53 \%$ compared with $11 \%$ in the control group. Thus with refinements in technique there is some prospect of an immunological profile being of diagnostic value in patients who have opaque media or a questionable diagnosis.

Little difference was found between groups of people subdivided by sex, site of primary tumour, and gross and microscopic features of the tumours, and this supports previous findings. ${ }^{16-18} \mathrm{~A}$ striking exception is the fact that patients whose tumours showed transcleral and episcleral extension were very much more often reactive than patients whose tumours were confined to the globe. This finding is in keeping with the view that the interior of the eye is to some extent an immunologically privileged site and suggests that the autoimmunising capacity of the cells of an ocular malignant melanoma is greatly increased once these cells penetrate beyond the sclera. ${ }^{19}$ The failure of the tests to provide prognostic indicators was disappointing, as no correlation was found with survival rate.

In summary the studies undertaken support previous reports of autoimmunogenic tumourassociated antigens on malignant melanomas in general and ocular malignant melanomas in particular. In our view the tests are not at present applicable in a routine fashion as diagnostic or prognostic aids in malignant melanoma. This opinion is based on the technical complexity of tests employed and also the high levels of false positivity and false negativity. We therefore require more refined tests that can be applied on a large scale and which would have a markedly higher rate of reaction within the melanoma patients and a considerably lower reaction frequency in the control donors. False positive results suggest that inflammation or other non-tumorous processes may lead to transient immune responses. Further purification of ocular melanoma antigens and sequential studies may assist in refining the specificity of the tests employed, and perhaps access to free antigen in the aqueous humour might produce a more reliable source of information.

\section{References}

1 Foulds WS. Ocular melanoma. In: McKie RM ed. Pigment cell. Basel: Karger, 1983; 6: 127-49.

2 Shields JA. Diagnosis and management of intraocular tumours. St Louis: Mosby, 1983.

3 Thomas JV, Green WR. Melanotic uveal tumours. In: Garner A, Klintworth GK, eds. Pathobiology of ocular disease. New York: Dekker, 1983: 651-88.

4 Rahi AHS. Immunology of ocular tumours. In: Garner A, Klintworth GK, eds. Pathobiology of ocular disease. New York: Dekker, 1983: 823-42.

5 Cochran AJ. Man cancer and immunity. London: Academic Press, 1978.

6 Bendixen G, Søborg M. A leucocyte migration technique for in vitro detection of cellular (delayed type) hypersensitivity in man. Dan Med Bull 1969; 16: 1-6.

7 Ross CE, Cochran AJ, Hoyle DE, Grant RM, McKie RM. Formalised tumour cells in the leucocyte migration inhibition test. Clin Exp Immunol 1975; 22: 126-32.

8 Morrison LJ, Cochran AJ, McKie RM, Ross CE, Todd G, Garland C. A study of patients with malignant melanoma using an indirect leucocyte migration assay. Int J Cancer 1979; 21: 11-6.

9 Cochran AJ, McKie RM, Ross CE, Ogg LJ, Jackson AM. Leucocyte migration inhibition by cancer patients sera. Int $J$ Cancer 1976; 18: 274-81.

10 Felberg NT, Pro-Landazuri JM, Shields JA, Federman JL. Tumour-associated antibodies in the serum of patients with ocular melanoma III. Immunoperoxidase detection. Arch Ophthalmol 1979; 97: 256-9.

11 Rahi AHS. Autoimmune reactions in uveal melanoma. Br J Ophthalmol 1971; 55: 793-807.

12 Malaty AHA, Rahi AHS, Garner A. Ostensible anti melanoma antibodies in patients with non-malignant eye disease. In: Silverstein AM, O'Connor GR, eds. Immunology and immunopathology of the eye. New York: Masson, 1979: 216-22.

13 Felberg NT, Donoso LA, Federman JL. Tumour-associated antibodies in the serum of patients with ocular melanoma. IV Correction for smooth muscle antibodies. Ophthalmology 1980; 87: 529-33.

14 Char DH, Jerome L, McCoy JL, Herberman RB. Cell-mediated immunity to melanoma-associated antigens in patients with ocular malignant melanoma. Am J Ophthalmol 1975; 79: 812-6.

15 Manor RS, Livni E, Joshua H, Ben-Sira I. Inhibition of macrophage migration by choroidal malignant melanoma-associated antigens in patients with uveal melanoma. Invest Ophthalmol Visual Sci 1978; 17: 684-7.

16 Char DH. Inhibition of leukocyte migration with melanomaassociated antigens in choroidal tumours. Invest Ophthalmol Visual Sci 1977; 16: 176-9.

17 Felberg NT, Federman JL, Shields JA, Michelson JB. Tumourassociated antibodies in patients with ocular melanoma. In: Silverstein AM, O'Connor GR eds. Immunology and immunopathology of the eye. New York: Masson, 1979: 202-8.

18 Kalafut F, Gernak A, Pham Manh Hung. Detection of specific immunoreactivity by LAI assay in patients with malig- 
nant melanoma of uveal tissue. Neoplasma 1979; 26: 299-305.

19 Noor Sunba MS, Rahi AHS, Morgan G, Holborow EJ. Lymphoproliferative response as an index of cellular immunity in malignant melanoma of the uvea and its correlation with the histological features of the tumour. Br J Ophthalmol 1980; 64: 576-90. 